\title{
IN THE CLASSROOM
}

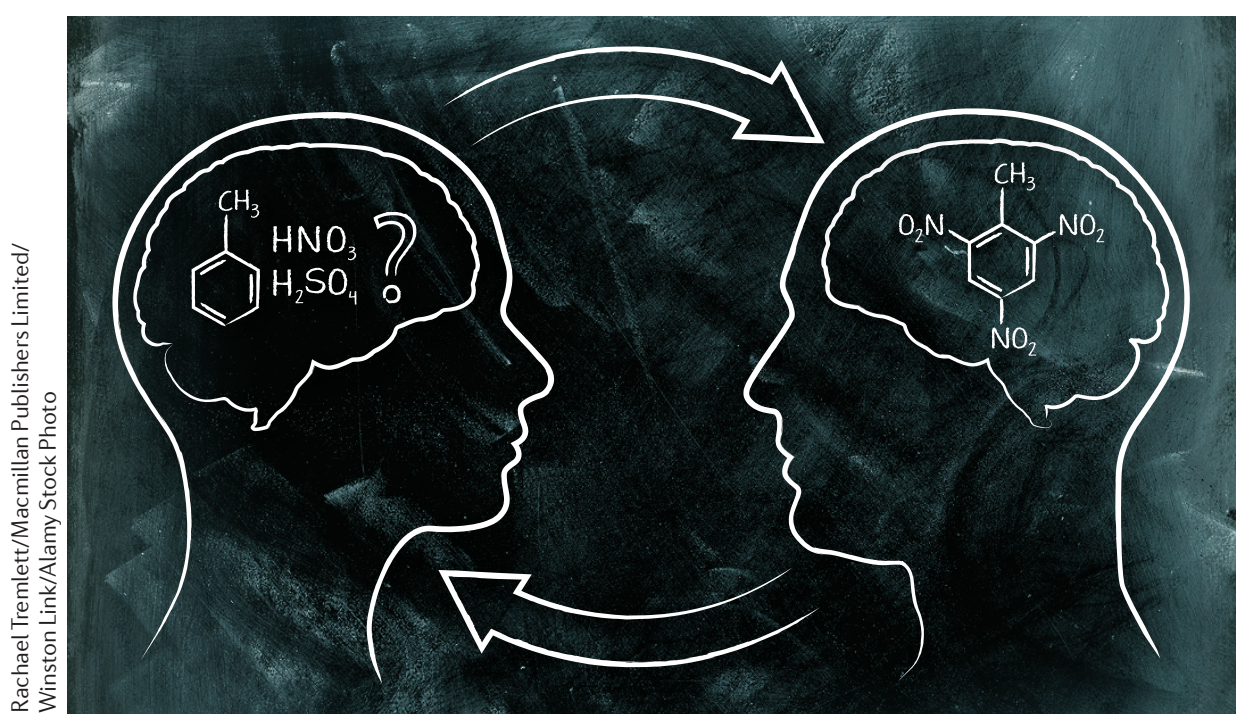

\section{Need to know}

\section{Simon Lancaster}

\section{Why do you need to know about chemistry education?}

The Nature Reviews Chemistry editorial team know that you were probably not attracted to the pages of this journal by the prospect of an insight into the world of chemistry education. Chemistry is a very broad church and that diversity is positively reflected in the Review articles presented herein. Yet what unites readers, authors and editors is a shared experience - we have all been chemistry students. There was a time when the sophisticated concepts we now take for granted were intimidating obstacles; when the language of chemistry was as foreign to us as any regional or cultural vernacular. These are topical issues in chemical education, and future columns will explore ideas such as threshold concepts and the lexicon of chemistry.

We are further united by the quest for impact. An article in this journal will inform dozens of research groups. The chemistry described within them has the potential to save lives, money or perhaps even our environment. These are powerful motivators rightly recognized by indices, frameworks and funders. The chemistry educator is also motivated by impact; everyone can remember an inspirational teacher. An 'effective educator' - itself a contested term we propose to scrutinize - has the potential, over the span of their career, to influence thousands of students. If we can marginally improve their chemical understanding, what effect would this have? What benefits would follow for our discipline and society from even incremental improvements in the teaching of such a central discipline?

We recognize that there is a very real challenge in presenting chemistry education to the readers of this journal. The vast majority of readers will have already completed a large part of their chemistry education, and only a fraction of a per cent of students who study chemistry as undergraduates in our higher education institutions will go on to become chemistry academics. For many of our readers the perception of the prevailing education system is that it has been successful. After all, it worked. This is a misleading assumption. For some, a few captivating lectures and a heavy dose of independent learning will always be enough. Some students have the benefit of exceptional teaching, others will succeed despite their learning experience. But, what about the huge increase in the proportion of young people that now go on to higher education? Of these, consider those who will move away from chemistry. Might they need a little more support than what sufficed for you? Admittedly, the clear majority graduate with 'good' chemistry degrees, satisfying the baseline measure of success. How confident can we be that they have a lasting conceptual understanding of our discipline?

You have been drawn to the pages of what you rightfully believe will be the premier source of chemistry reviews by the desire to explore the very latest developments in your field of chemistry research. None of us would dream of embarking on a new chemical endeavour without ensuring we were familiar with the cutting edge. Both academics and research students would not handicap themselves by using outmoded instruments. But are the same standards applied when a new chemistry course is designed? Are evidence-based techniques gleaned from the science education literature applied at our institutions or do teachers simply teach the way that they were taught? Are curricula forward-looking and equally concerned with the attributes sought in twenty-first century chemistry graduates or are they the same content heavy syllabus that has always been presented? We plan to explore issues ranging from the debate between transmissionist and constructivist schools of teaching to the transition between student and expert. At what point do you become 'an expert chemist'?

A particular goal of this column will be to cut through the misinformation surrounding education research. Intuitive notions, such as learning styles, remain prevalent in higher education despite their having no evidence base and having been thoroughly debunked (Psychological Science in the Public Interest 9 , $106-116 ; 2008)$ : you use $100 \%$ of your brain, not $10 \%$.

Although there are countless journals on science education, chemistry education is primarily served by two: the Journal of Chemical Education by the American Chemical Society (J. Chem. Educ. 92, 399-400; 2015) and Chemistry Education Research and Practice by the Royal Society of Chemistry (Chem. Educ. Res. Pract. 16, 6-8; 2015). According to the 2015 Journal Citation Reports (Thomson Reuters, 2016), their respective impact factors are 1.225 and 1.802 - modest compared with mainstream chemistry research journals. Similarly, the value of citation-based metrics alone is 


\section{IN THE CLASSROOM}

questionable in a field where there are many interested readers but relatively few conducting research. Altmetric scoring may be revealing in this regard: a recent article (Proc. Natl Acad. Sci. USA 111, 8410-8415; 2014) by Freeman et al. is just one example of how the significance of such research extends far beyond citations.

So, what is chemical education and, indeed, what is chemistry education? The fact that two ostensibly similar journals each respectively use one of these expressions suggests that they are interchangeable. However, the leading monograph in the field sets out to clearly differentiate the two terms (Chemistry Education Wiley-VCH; 2015). Mahaffy argues that chemical education reflects a focus on substances, whereas chemistry education places human activity at the centre of the field. By focusing on chemistry and not chemicals, he argues that we can recognize the importance of authenticity and context on students' learning.

\section{For many of our readers the perception of the prevailing education system is that it has been successful. After all, it worked 5}

I have less time for the distinction between chemistry education and chemical education, not because the arguments have no merit but because I believe such discussions risk appearing insular and pedantic. There is no sense in which holders of posts in chemical education and the authors of articles submitted to Journal of Chemical Education do not have the interests of the learner foremost. The impact of chemistry education as an academic discipline depends on its accessibility to all chemists, which is why this editorial initiative is so significant.
Chemistry education is no more a static subject than any other field of chemistry. The skills of our students are constantly evolving; the boundaries of our discipline are blurring. In many cases, the chemistry educationalist has foregone the laboratory for the lecture theatre. However, there remains an experimental spirit to constantly refine and improve, to reflect, theorize and optimize, and to share the lessons learnt. We have much to offer each other.

Simon Lancaster is at the University of East Anglia, Norwich Research Park, Norwich, Norfolk NR4 7TJ, UK s.lancaster@uea.ac.uk

doi:10.1038/s41570-016-0006 Published online 11 Jan 2017 The author declares no competing interests.

\section{FURTHER INFORMATION}

Altmetric scoring: https://www.altmetric.com/ details/2345524

ALL LINKS ARE ACTIVE IN THE PDF 